\title{
Radiative forcing of the desert aerosol at Ouarzazate (Morocco)
}

\author{
Abdelouahid TAHIRI ${ }^{1 *}$ and Mohamed DIOURI ${ }^{1}$ \\ ${ }^{1}$ Atmosphere Physics Team (LME), Faculty of Sciences, Mohammed First University, \\ Oujda, 60000 Morocco
}

\begin{abstract}
The atmospheric aerosol contributes to the definition of the climate with direct effect, the diffusion and absorption of solar and terrestrial radiations, and indirect, the cloud formation process where aerosols behave as condensation nuclei and alter the optical properties. Satellites and ground-based networks (solar photometers) allow the terrestrial aerosol observation and the determination of impact. Desert aerosol considered among the main types of tropospheric aerosols whose optical property uncertainties are still quite important. The analysis concerns the optical parameters recorded in 2015 at Ouarzazate solar photometric station (AERONET/PHOTONS network, http://aeronet.gsfc.nasa.gov/) close to Saharan zone. The daily average aerosol optical depth $\tau_{\text {aer }}$ at $0.5 \mu \mathrm{m}$, are relatively high in summer and less degree in spring (from 0.01 to 1.82). Daily average of the Angstrom coefficients $\alpha$ vary between 0.01 and 1.55 . The daily average of aerosol radiative forcing at the surface range between -150 $\mathrm{W} / \mathrm{m}^{2}$ and $-10 \mathrm{~W} / \mathrm{m}^{2}$ with peaks recorded in summer, characterized locally by large loads of desert aerosol in agreement with the advections of the Southeast of Morocco. Those recorded at the Top of the atmosphere show a variation from $-74 \mathrm{~W} / \mathrm{m}^{2}$ to $+24 \mathrm{~W} / \mathrm{m}^{2}$.
\end{abstract}

\section{Introduction}

The desert aerosol observed in Morocco is composed of mineral particles of Saharan origin of size between 0.1 and 10 microns. These particles are raised by the wind over arid and semi-arid regions, remain omnipresent in the atmosphere, and can move over several hundred kilometres. Aerosols in the atmosphere have different physical and chemical characteristics, the effects of which depend on the wavelengths of light. The evolution in time and space of aerosols has a significant influence on the accurate assessment of atmospheric transmission related to their presence. The determination of the physical properties of the tropospheric aerosol constitutes an important field of research enabling the improvement of climate models. Aerosols still represent one of the main sources of error in the forecast of the climate, by the significant uncertainty that they introduce in the evolution of the radiative forcing. This fact results from the great spatial and temporal variability of the tropospheric aerosol, its concentration and composition are quite variable, as it comes from different sources. This study presents the data concerning the optical properties of the Moroccan desert aerosol based on the measurements obtained by the AERONET /

\footnotetext{
*dyourim@gmail.com
} 
PHOTONS network. Several studies have used solar photometers from the ground to characterize the aerosol in different regions of the globe [1], [2], [3], [4], [5] and [6]. Measurement campaigns to determine Saharan mineral dust microphysical characteristics such as the SAMUM measurement campaign carried out in May-June 2006 near Zagora (Tamgroute Village) and Ouarzazate [7], [8] and [9]. In the same, the AMMA campaign took place from mid-January to 2 February 2006 in the region (Niger, Benin and Nigeria) to characterize dynamics during the dry season in West Africa. We will analyze the results of the measurements made for the Moroccan site of Ouarzazate. These analyzes concern the aerosol optical thickness (AOT), the Angstrom coefficient $(\alpha)$, the volume distribution and the radiative forcing at the surface and at the top of the atmosphere (ARF).

\section{Materials and methods}

\subsection{AERONET/PHOTONS network}

The Goddard Space Flight Centre (NASA, USA) and the Atmospheric Optics Laboratory (CNRS, France) set up the AERONET / PHOTONS network. It collects measurements made on the ground by solar photometers to specify the optical and microphysical properties of the particles contained in the atmosphere. The data are available from more than one thousand one hundred stations across the globe. The network instruments checked and calibrated with an identical protocol. The data processed in the same way regardless of the date and place of acquisition, whether for the inversion itself [10] or for the rejection of the affected measurements in the presence of clouds [11]. The CIMEL CE-318 solar photometer (Figure 1) is an instrument allowing the restitution of the vertically optical integrated aerosols on the atmospheric column. Photometric measurements are possible only during the day when the sun is visible and in the absence of clouds. The automatic photometer, developed in France by the Laboratory of Atmospheric Optics (Lille), description made by [12]. The photometer is equipped with a robot with two axes allowing movements in the zenith and azimuth planes and can target any point of the celestial cost with an accuracy of $0.05^{\circ}$ and a field of view of $1.2^{\circ}$. It has a filter wheel in eight channels $(0.34 ; 0.38 ; 0.44 ; 0.50 ; 0.675 ; 0.87 ; 1.02$ and $1.64 \mu \mathrm{m}$, Table 1$)$. These spectral filters with a width of $0.01 \mu \mathrm{m}$ correspond to atmospheric windows in which the absorption of solar radiation by the gaseous compounds is low. A geostationary satellite transmits data, every four hours, to NASA's Goddard Space Flight Centre. The photometer provides direct solar view measurements as well as scattering measurements according to the angular luminance distribution of the sky $\left(\mathrm{W} / \mathrm{m}^{2}\right.$.Sr. $\mu \mathrm{m}$ ) in the Almucantar (circle of the same solar elevation including the sun, retaining the zenith angle $\theta_{\mathrm{v}}$ constant, Figure 2). Several morning and afternoon of Almucantar measurement sequences performed. For a sequence of measurements according to the directions Almucantar $A_{i}$ over $2 \pi(\mathrm{rad})$, on average $35 \mathrm{~s}$.

There are different levels of data processing available: level 1.0 (raw data), level 1.5 (the cloud mask applied while the final calibration not necessarily performed) and level 2.0 (the cloud mask applied as well as the final calibration). We use for our study level 2.0. The algorithm used in AERONET [10] and [13] characterizes aerosols by equating simulated luminance with a radiative transfer code to luminance measurements (direct sunlight luminance and sky luminance) obtained at 4 wavelengths. $(0.440,0.675,0.870$ and 1.020 $\mu \mathrm{m})$. Radiative transfer is related to the refractive indices (and wavelength dependent) of aerosols and their distribution. The use of this radiative transfer code makes it possible to determine by inversion the desired optical properties with a minimum of initial hypotheses (spherical particles, homogeneous and lognormally distributed). Several studies with other radiative transfer codes involving nonlinear inversion methods [14] and [15] allowed the determination of the optical properties of the desert aerosol. The most recent [16] proposed for particles of non-spherical shapes. 


\subsection{Ouarzazate solar-photometer}

The Ouarzazate site $\left(30.92{ }^{\circ} \mathrm{N}, 6.91{ }^{\circ} \mathrm{W}, 1136 \mathrm{~m}\right)$ is associated with the meteorological station. Ouarzazate is a small town with almost no industrial activity. It is located southeast of the Atlas and north-west of the Sahara. Ouarzazate has a pre-Saharan climate characterized by low rainfall. In summer, the climate is hot and dry. The average maximum temperature in July is $40^{\circ} \mathrm{C}$, the average minimum is $25^{\circ} \mathrm{C}$. In January, the minimum and maximum average temperatures are respectively $2{ }^{\circ} \mathrm{C}$ and $16^{\circ} \mathrm{C}$, in the middle of the night, the temperature can go down to $-4^{\circ} \mathrm{C}$. In the spring, clouds are rare and storms are exceptional. Desert winds (Sirocco and Chergui) play an important role in the climate of Ouarzazate (http://fr.wikipedia.org/wiki/Ouarzazate, AERONET).

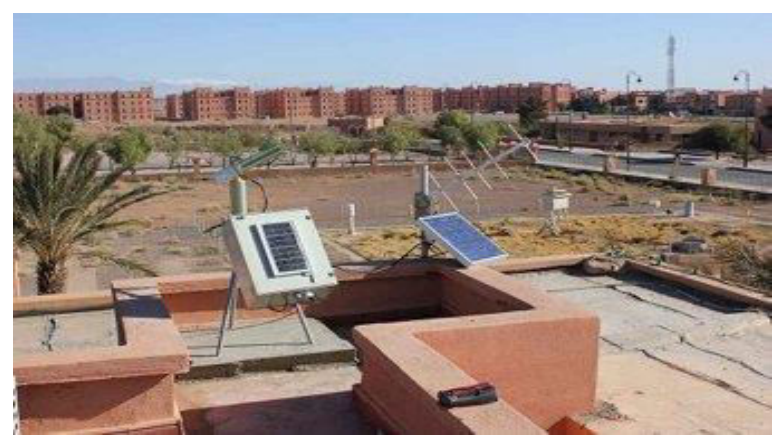

Fig.1. Ouarzazate site

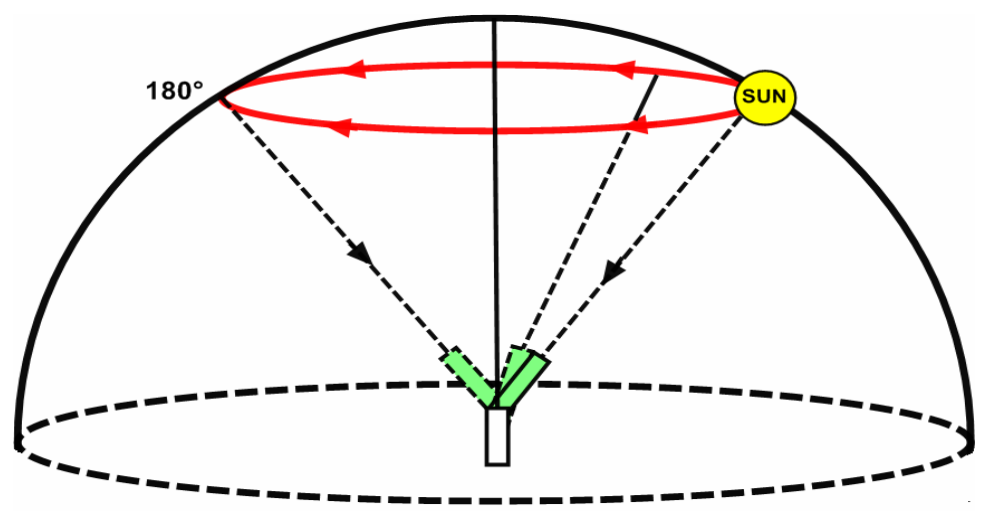

Fig. 2. ALMUCANTARAT position 
Table 1. Spectral wavelengths $(\mu \mathrm{m})$

\begin{tabular}{l|l}
\hline$\lambda$ Standard $(\mu \mathrm{m})$ & Level 2.0 \\
\hline $0.340(0.002 \mu \mathrm{m})$ & Ray, $\mathrm{NO}_{2}, \mathrm{O}_{3}$ \\
$0.380(0.004 \mu \mathrm{m})$ & Ray, $\mathrm{NO}_{2}$ \\
$0.440(0.010 \mu \mathrm{m})$ & Ray, $\mathrm{NO}_{2}$ \\
$0.500(0.010 \mu \mathrm{m})$ & Ray, $\mathrm{NO}_{2}, \mathrm{O}_{3}$ \\
$0.675(0.010 \mu \mathrm{m})$ & Ray, $\mathrm{O}_{3}$ \\
$0.870(0.010 \mu \mathrm{m})$ & Rayleigh \\
$1.020(0.010 \mu \mathrm{m})$ & Ray, $\mathrm{H}_{2} \mathrm{O}$ \\
$1.640(0.025 \mu \mathrm{m})$ & Ray, $\mathrm{H}_{2} \mathrm{O}, \mathrm{CO}_{2}, \mathrm{CH}_{4}$ \\
\hline
\end{tabular}

\section{Results and analysis}

\subsection{Aerosol Optical Thickness (AOT) and Angstrom Coefficient ( $\alpha$ )}

The aerosol optical thickness (EOA), denoted $\tau_{\text {aer }}(\lambda)$ is dimensionless, it quantifies the extinction of incident radiation in a column of atmosphere, both by absorption and by diffusion. $\tau_{\text {aer }}$ is a key physical parameter for the aerosol characterization, it gives an indication of atmospheric aerosol content. The study of the annual evolution of the AOT allows analyzing the changes in the aerosol type and concentration between the different seasons. Aerosol optical thicknesses can reach very high values, for sandstorms, it is common practice to observe aerosol optical thicknesses at $0.5 \mu \mathrm{m}$ exceeding 2 , which can even exceed 4 above the continent African [17]. The direct measuring the aerosol optical thickness is the measurement of the attenuation by the atmosphere of direct solar radiation. The decrease in solar flux expressed by Bouguer law:

$$
I(\lambda)=I_{0}(\lambda) e^{-m_{\text {air }} \tau(\lambda)}
$$

$\tau(\lambda)$ is the total optical thickness that accounts for the contribution to aerosol attenuation, Rayleigh scattering and atmospheric gases.

$$
\begin{gathered}
\tau(\lambda)=\tau_{\text {aér }}(\lambda)+\tau_{\text {Ray }}(\lambda)+\tau_{\text {gaz }}(\lambda) \\
\tau_{\text {aér }}(\lambda)=\frac{1}{m_{\text {air }}} \ln \left(\frac{I_{\mathrm{o}}(\lambda)}{I(\lambda)}\right)-\tau_{\text {Ray }}(\lambda)-\tau_{\text {gaz }}(\lambda) \\
\tau_{\text {Ray }}(\lambda)=\frac{p}{p_{0}} 0.00877 . \lambda^{-4.05}
\end{gathered}
$$

$\mathrm{I}(\lambda)$ : solar flux $(\mathrm{W} / \mathrm{m} 2)$;

$\mathrm{I}_{0}(\lambda)$ : extraterrestrial solar flux $(\mathrm{W} / \mathrm{m} 2)$

$\boldsymbol{\tau}_{\text {gaz }}(\lambda)$ : optical thickness due to gas absorption $\left(\mathrm{O}_{3}, \mathrm{NO}_{2}, \mathrm{CH}_{4}\right.$ and $\left.\mathrm{H}_{2} \mathrm{O}\right)$ [19] and [20];

$\tau_{\text {Ray }}$ : Optical thickness due to Rayleigh scattering [21]

mair : air mass [22];

$\theta_{\mathrm{v}}:$ zenithal angle $\left(^{\circ}\right)$;

$\mathrm{P}$ : atmospheric pressure; $\mathrm{P}_{0}$ : standard atmospheric pressure at sea level.

The turbidity coefficient of Angström $\beta$, represents the optical thickness of the wavelength

$1 \mu \mathrm{m}$. For a wavelength different from $1 \mu \mathrm{m}$, the AOT is related to this coefficient by:

$$
\tau_{a e ́ r}(\lambda)=\beta \lambda^{-\alpha}
$$


$\beta$ varies in the range 0 to 0.5 , it is an index which represents the quantity of the aerosol present in the atmosphere in a vertical direction (atmospheric load), $\beta$ can exceed the value 0.5 for a very charged atmosphere.

The Angstrom coefficient $\alpha$ depends on the aerosol particle size distribution. $\alpha$ close to 0 is associated with large loads of large particles introduced by thermal instability or by a sandstorm (the optical thicknesses vary slowly with the wavelength) whereas $\alpha$ around 4 indicate that the particle population is mainly nucleation and accumulation (very fine to fine particles, optical thicknesses vary more rapidly with wavelength). A population of large particles whose number distributed in one mode may have a slightly negative Angstrom coefficient. The upper limit of $\alpha$ corresponds to the spectral behavior of the attenuation optical thickness associated with particles much smaller than the wavelength, such as gaseous molecules of the atmosphere (Rayleigh scattering). The lower limit corresponds to the case where the particle size is much greater than the wavelength. The micro droplets of water contained in the clouds correspond to this condition; in this case, all the visible wavelengths diffuse in the same way. To quantify the variation of the Angstrom coefficient, the data of the AOTs use for two respective wavelengths. We define the Angstrom coefficient:

$$
\alpha_{1-2}=-\frac{\ln \left(\frac{\tau_{\text {aér }}\left(\lambda_{1}\right)}{\tau_{\text {aér }}\left(\lambda_{2}\right)}\right)}{\ln \left(\frac{\lambda_{1}}{\lambda_{2}}\right)}
$$

For our study, we put $\lambda_{1}=0.44 \mu m$ and $\lambda_{2}=0.87 \mu m$.

The monthly averages of the aerosol optical thicknesses at $0.5 \mu \mathrm{m}$ (Figure 4) and the Angstrom coefficients $(0.44-0.87 \mu \mathrm{m})$ observed in Ouarzazate for the year 2015. The peaks of AOT register in summer. The type of aerosol alternately changes in the Ouarzazate region due to the low influence associated with the Atlantic air masses that moderates the air dust loads of East and Saharan origin on summer. The minimum values recorded during the fall and winter. During the SAMUM experimental measurement campaign carried out in May-June 2006 in Ouarzazate, the daily average of the AOTs at $0.5 \mu \mathrm{m}$ wavelength is 0.28 [23], in agreement with the AERONET data (Figure 4). For the Angstrom coefficients, it noted that the largest values of the optical thicknesses of the aerosol are associated with small values of the Angstrom coefficients $\alpha$ characteristic of the presence of desert dust in summer coming mainly from the Southeast. 


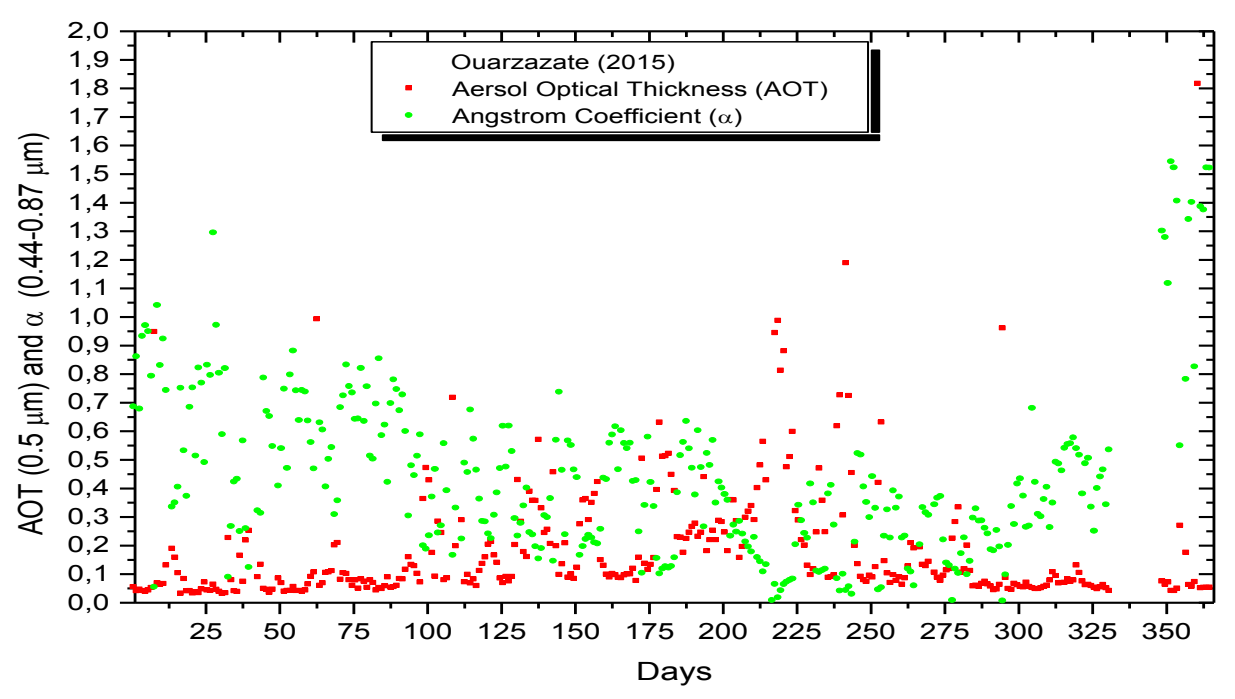

Fig. 3.Time series of AOT $(0.5 \mu \mathrm{m})$ and Angstrom Coefficient $(0.44-0.87 \mu \mathrm{m})$ observed at Ouarzazate (2015)

\subsection{Aerosol Particle Size Distribution}

The monthly averages of volume particle distributions show two modes (Figure 4), the main is that of coarse particles. The fine particles are around $0.15 \mu \mathrm{m}$ and the coarse close 2 $\mu \mathrm{m}$. The annual volume concentration of fine particles varies between 0.010 and 0.021 $\mu \mathrm{m}^{3} / \mu \mathrm{m}^{2}$, whereas for large particles it varies between 0.086 and $0.126 \mu \mathrm{m}^{3} / \mu \mathrm{m}^{2}$. The parameters of the distributions record high values in summer where one observes important advections of the masses of air coming mainly from Southeast of Morocco. 

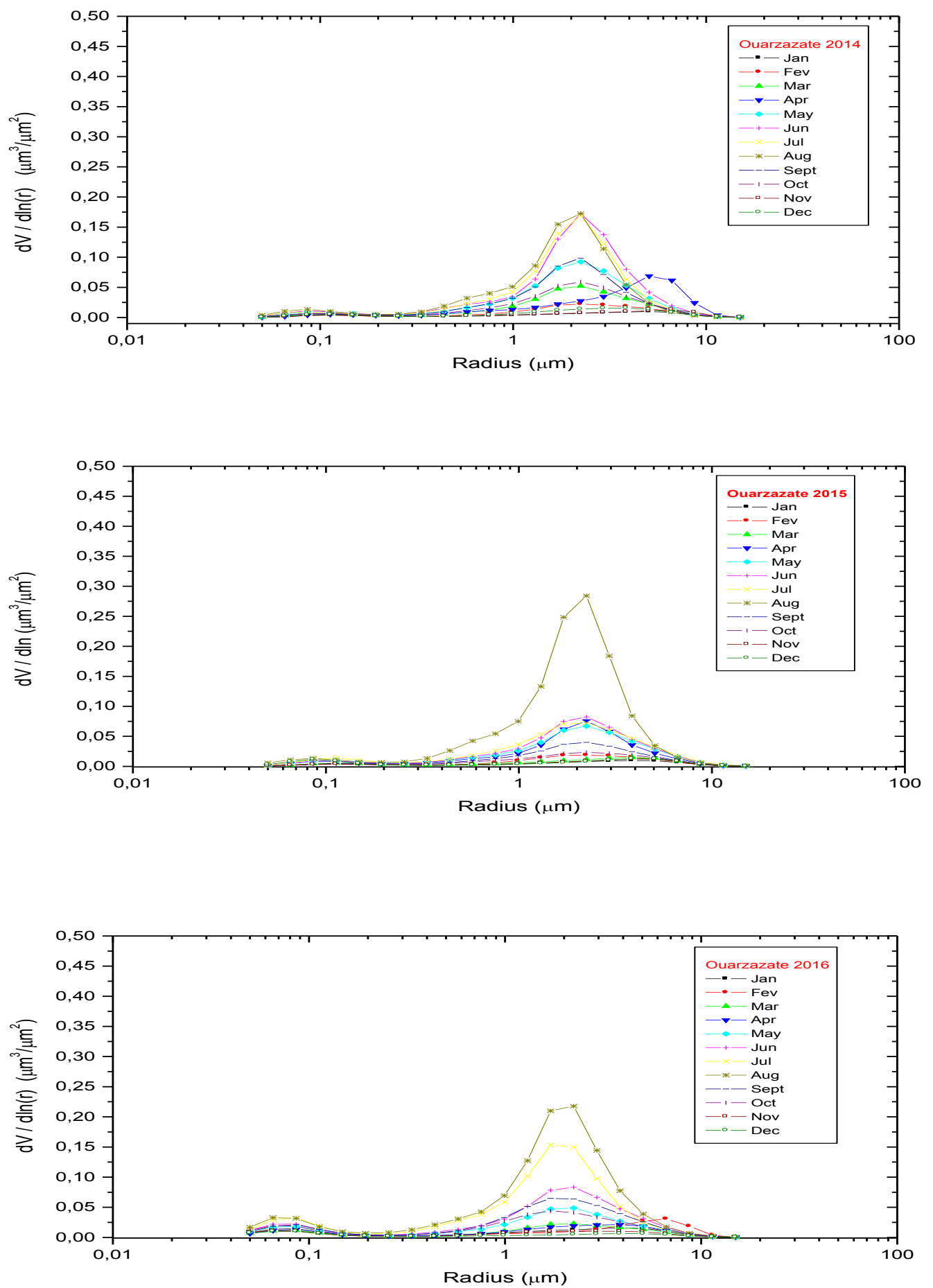

Fig. 4. Monthly averages of volume distributions (2014, 2015 and 2016) 


\subsection{Aerosol Radiative Forcing ARF}

The aerosol radiative forcing $\left(\mathrm{W} / \mathrm{m}^{2}\right)$ corresponds to any modification of the net radiative flux at the altitude $\mathrm{z}$ due to atmospheric aerosol. Positive radiative forcing tends to warm up the Earth's system, whereas a negative forcing tends to cool it. It quantified at the top of the atmosphere or at the ground surface according to the equation:

$$
\Delta F_{z}=\left(F^{\downarrow}-F^{\uparrow}\right)-\left(F^{\downarrow 0}-F^{\uparrow 0}\right)
$$

$\mathrm{F}^{\uparrow}$ (visible + infrared) is the total ascending flow and $\mathrm{F}^{\downarrow}$ (visible + infrared) is the descending one. The indices $\left(\uparrow^{0}\right)$ and $\left(\downarrow^{0}\right)$ correspond to the flows calculated in absence of aerosol, case of very clear sky. A clean atmosphere without aerosol characterized by a maximum of global irradiance, a minimum of diffuse irradiance and low optical thicknesses. The radiative forcing of aerosols depends on the intrinsic properties of the aerosol but also on the relative humidity of the air as well as the albedo of the soil surface.

The daily average radiative forcing values at the surface and at the top of the atmosphere (Figure 5) show a variation from -150 to $-10 \mathrm{~W} / \mathrm{m}^{2}$ with significant variations observed in spring and summer. For these seasons, there are decreases in net flux to the Earth's surface. The values at the top of the atmosphere vary between -74 and $+24 \mathrm{~W} / \mathrm{m}^{2}$, the negative values mean the increase of the flux at the top of the atmosphere due to the diffusion of the radiation towards the space by the aerosols thus contributing to the significant cooling of the Earth-Atmosphere system. While, the positive values indicate a greater amount of radiative energy reflected by the cirrus passengers.

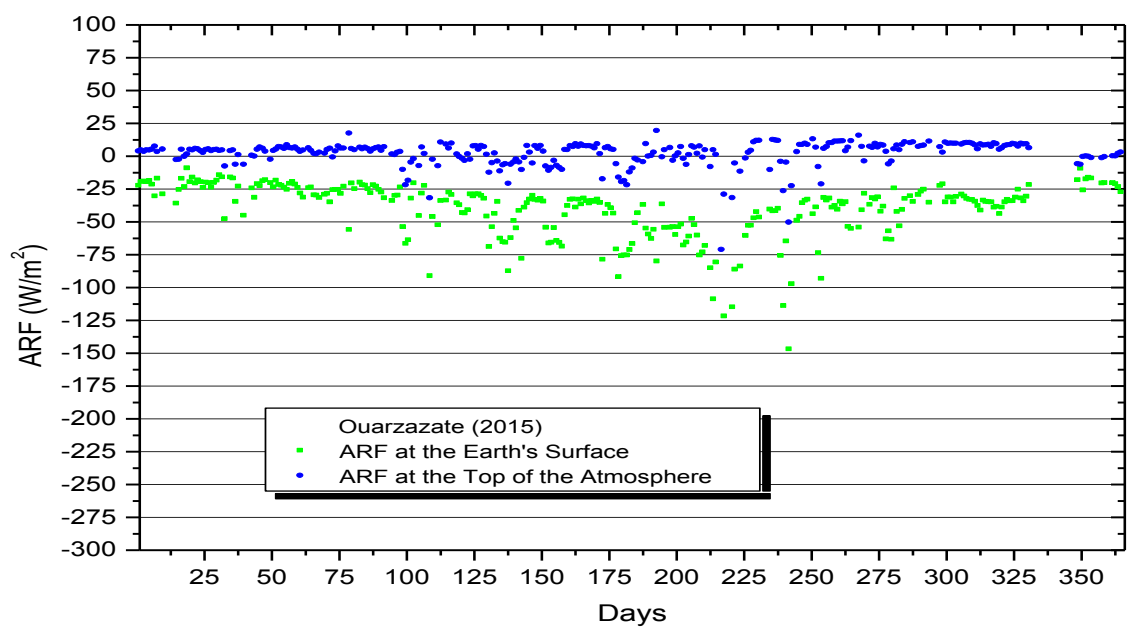

Fig. 5. Aerosol Radiative Forcing at the Earth's Surface and at the Top of the Atmosphere Observed at Ouarzazate in 2015. 


\section{Conclusion}

Monthly averages of atmospheric aerosol optical thicknesses obtained at the Ouarzazate site confirm the importance of the influence of desert aerosol with relatively high values in summer and to a lesser degree in spring. The daily mean values of the $\alpha$-Angstrom coefficients vary between 0.01 and 1.55 . The low characteristic values of large particles and corresponding to the presence of desert dust appear in summer. The volume distributions of the aerosol mainly characterized by a mode at $2 \mu \mathrm{m}$ and a second mode of very small importance at $0.15 \mu \mathrm{m}$. The trace of presence of the desert aerosol emitted regularly from the South and Southeast of Morocco confirmed at the aerosol optical parameters cyclically observed for the three years.

Monthly averages of aerosol radiative forcing at the surface and at the top of the atmosphere obtained at the Ouarzazate site for 2015 confirm the influence of the desert aerosol. The large ARF values correspond to the large values of the AOTs. The values at the top of the atmosphere vary between -74 and $+24 \mathrm{~W} / \mathrm{m}^{2}$, the negative values correspond to the increase of the flux due to the diffusion of the radiation towards the space by the aerosols contributing significantly to cooling the Earth-Atmosphere system. Positive values indicate a greater amount of radiative energy reflected by the importance of the cirrus passengers. At the surface, ARF values vary between $-150 \mathrm{~W} / \mathrm{m}^{2}$ and $-10 \mathrm{~W} / \mathrm{m}^{2}$, are quite representative of the importance of forward scatter of the coarse particle modes characteristic of desert aerosols which cause a decrease in the net flux at the ground surface.

\section{Aknowledgements}

Authors want to thank Principal Investigator of AERONET Site (Ouarzazate): Emilio Cuevas-Agullo and M. Taoufik Zaidouni.

\section{References}

1. P.C.S. Devara, G. Pandithurai, P.E. Raj, S. Sharma. Investigations of aerosol optical depth variations using spectroradiometer at an urban station, Pune, India. J. Aerosol Sci., 27, 621- 632(1996).

2. M. Diouri et D. Chabane, 2010. AERONET/PHOTONS (http://aeronet.gsfc.nasa.gov/ ).

3. L. El Amraoui and Diouri. M. Characterisation of different air mass influences in terms of aerosol optical parameters.J.Aerosol Sci.Vol 32 Supp 1 pp S643-S644 (2001).

4. I. El Aouadi. Estimation de la quantité de vapeur d'eau précipitable et du forçage radiatif de l'aérosol atmosphérique à partir de la télédétection passive à Oujda (Maroc). Thèse de Doctorat,Université Mohamed Premier, Faculté des sciences, Oujda, Maroc (2005).

5. A. Tahiri. Etude de l'aérosol désertique avec des données actuelles, DESA. Université Mohamed Premier, Faculté des sciences, Oujda, Maroc (2006).

6. W. von Hoyningen-Huene et Posse. P. Nonsphericity of aerosol particles and their contribution to radiative forcing. J. Quant. Spectrosc. Radiat. Transfer, 57, 651-668 (1997).

7. K. Kandler. Et al. Size distribution, mass concentration, chemical and mineralogical

composition and derived optical parameters of the boundary layer aerosol at Tinfou, Morocco, during SAMUM 2006. Tellus 61B, 32-50 (2009).

8. A. Petzold et al. Saharan dust absorption and refractive index from aircraft-based observation during SAMUM 2006. Tellus 61B, 118-130. DOI: 10.1111/j.16000889.2008.00383.x (2009).

9. A. Tahiri et Diouri. M. Premier colloque francophone sur les Polluants Organiques Générés par l'Agriculture et les Transports POGAT 2011. Epaisseur optique de l'aérosol désertique observé à Ouarzazate et Zagora. 24 - 27 Octobre 2011, Agadir, Maroc. 
10. O. Dubovik and King M.D. A flexible inversion algorithm for retrieval of aerosol optical properties from sun and sky radiance measurements. Journal of Geophysical Research, 105, 20673-20696 (2000).

11. A. Smirnov., Holben. B. N., Eck T.F., Dubovik. O \& Slutsker. I. Cloud screening and Quality control algorithms for the AERONET data base. Remote Sensing of Environment, 73, 73337-73349 (2000).

12. B. N. Holben et al. AERONET- A federated instrument network and data archive for aerosol characterization. Remote Sensing of Environment, 66, 1-16 (1998).

13. O. Dubovik., A. Smirnov., B. N. Holben., M. D. King., Y. J. Kaufman., T. F. Eck and I. Slutsker. Accuracy assessment of aerosol optical properties retrieval from AERONET sun and sky radiance measurements. Journal of Geophysical Research, 105, 9791-9806 (2000). 14. M. Diouri and Sanda. S.I. Deduction of particle size distribution from aerosol optical depth.CLEOPATRE-I code. J. Aerosol Sci, 28, S459 (1997).

15. W. von Hoyningene-Huene and Wendisch. M. Possibility of refractive index determination of atmospheric aerosol particles by ground based solar extinction and scattering measurements. Atmos. Environ, 28, 785-795(1994).

16. M.I. Mishchenko., Travis, L.D and Lacis, A.A. Multiple Scattering of Light by Particles. Radiative Transfer and Coherent Backscattering, Cambridge Univ Press, New York (2006).

17. A. Slingo et al. Observations of the impact of a major Saharan dust storm on the atmospheric radiation balance, Geophysical Research Letters, 33, 124817, doi :10.1029/2006GL027869 (2006).

18. W. v. Hoyningen-Huene. Atmospheric aerosol $-\mathrm{A}$ special topic in environmental physics . IUP, Universitat Bremen, 16/04/2003.

19. J.P.Burrows., Dehn, A., Deters, B., Himmelmann, S., Richter, A., Voigt, S and Orphal, J., Atmospheric Remote-Sensing Reference Data from GOME: Part 1. TemperatureDependent Absorption Cross-sections of $\mathrm{NO}_{2}$ in the 231-794 nm Range, JQSRT, 60, 10251031 (1998).

20. J.P.Burrows., Richter, A., Dehn, A., Deters, B., Himmelmann, S., Voigt, S. and Orphal J., Atmospheric remote -sensing-reference data from GOME: 2. Temperature -dependent absorption cross sections of $\mathrm{O}_{3}$ in the 231-794 nm range, JQSRT, 61, 509-517, 1999.

21. E.G. Dutton., Reddy. P., Ryan.S., Deluisi.J.J. Features and effects of aerosol optical depth observed at Mauna Loa, Hawaii: 1982-1992, J. Geophys. Res., 99, 8295-8306, (1994).

22. F. Kasten and Young. A.T. Revised optical air mass tables and approximation formula. Applied Optics, 28, 4735-4738 (1989).

23. C. Toledano et al. Spectral aerosol optical depth characterization of desert dust during SAMUM 2006.Tellus 61B, 216-228.Doi: 10.1111/ j.1600-0889. 2008. 00382.x (2009). 